\title{
Shifting up the optimum figure of merit of $p$-type bismuth telluride-based thermoelectric materials for power generation by suppressing intrinsic conduction
}

\author{
Li-Peng $\mathrm{Hu}^{1}$, Tie-Jun Zhu ${ }^{1,2,3}$, Ya-Guang Wang ${ }^{1}$, Han-Hui Xie ${ }^{1}$, Zhao-Jun $\mathrm{Xu}^{1}$ and Xin-Bing Zhao ${ }^{1,3}$
}

The abundance of low-temperature waste heat produced by industry and automobile exhaust necessitates the development of power generation with thermoelectric (TE) materials. Commercially available bismuth telluride-based alloys are generally used near room temperature. Materials that are composed of $p$-type bismuth telluride, which are suitable for low-temperature power generation (near $380 \mathrm{~K}$ ), were successfully obtained through Sb-alloying, which suppresses detrimental intrinsic conduction at elevated temperatures by increasing hole concentrations and material band gaps. Furthermore, hot deformation (HD)-induced multi-scale microstructures were successfully realized in the high-performance $p$-type TE materials. Enhanced textures and donor-like effects all contributed to improved electrical transport properties. Multiple phonon scattering centers, including local nanostructures induced by dynamic recrystallization and high-density lattice defects, significantly reduced the lattice thermal conductivity. These combined effects resulted in observable improvement of $Z T$ over the entire temperature range, with all TE parameters measured along the in-plane direction. The maximum $Z T$ of 1.3 for the hot-deformed $\mathrm{Bi}_{0.3} \mathrm{Sb}_{1.7} \mathrm{Te}_{3}$ alloy was reached at $380 \mathrm{~K}$, whereas the average $Z T_{\mathrm{av}}$ of 1.18 was found in the range of $300-480 \mathrm{~K}$, indicating potential for application in low-temperature TE power generation.

NPG Asia Materials (2014) 6, e88; doi:10.1038/am.2013.86; published online 21 February 2014

Keywords: bismuth telluride; donor-like effect; hot deformation; low-temperature power generation; texture

\section{INTRODUCTION}

Thermoelectric (TE) devices have attracted extensive interest over the past few decades because of their potential use in direct thermal-toelectrical energy conversion and solid-state refrigeration. The TE conversion efficiency of a material can be gauged by the dimensionless figure of merit $Z T=\alpha^{2} \sigma T / \kappa$, where $\alpha, \sigma, \kappa$ and $T$ are the Seebeck coefficient, the electrical conductivity, the thermal conductivity and the operating temperature, respectively. ${ }^{1}$ Continuous effort has been invested toward improving the $Z T$ values of TE materials, resulting in significant advances through phonon engineering ${ }^{2-9}$ and band engineering. ${ }^{10-14}$ For example, remarkable increases in $Z T$ have been achieved in bulk nanomaterials via the enhancement of phonon scattering at boundaries to reduce lattice thermal conductivities. ${ }^{2,4,6,7}$

Currently, the best commercial TE materials near room temperature are still rhombohedral bismuth tellurides and related solid solutions fabricated by unidirectional crystal growth. ${ }^{15-17}$ Nanostructuring strategies have been devised to prepare highperformance bismuth telluride-based alloys, including bottom-up and top-down approaches. In the bottom-up approach, nanostructures are first obtained by low-temperature hydrothermal synthesis, ${ }^{2,5}$ ball milling ${ }^{6,18,19}$ or melt spinning ${ }^{4,20}$ and are subsequently sintered and consolidated by hot pressing (HP) or spark plasma sintering to yield bulk alloys. Recently, Shen et al. ${ }^{7,21}$ have developed a novel top-down approach to improve the TE performance of $p$-type bismuth telluride-based alloys utilizing hot deformation (HD)-induced in situ nanostructures and high-density lattice defects. More recently, we found that HD can also be used to improve the TE performance of $n$-type bismuth telluride-based materials because of multi-scale microstructural effects including microscale texture enhancement, lattice defects and donor-like effects at the atomic scale, and recrystallization-induced local nanostructures. ${ }^{22,23}$

The ternary alloy $\mathrm{Bi}_{0.5} \mathrm{Sb}_{1.5} \mathrm{Te}_{3}$ has been so far the bestknown $p$-type materials for room-temperature refrigeration. Various advanced powder metallurgical techniques ${ }^{4,5,7}$ have been implemented to induce high $Z T$ values (approximately 1-1.3) in polycrystalline $\mathrm{Bi}_{0.5} \mathrm{Sb}_{1.5} \mathrm{Te}_{3}$ alloys through structural modification.

${ }^{1}$ State Key Laboratory of Silicon Materials, Department of Materials Science and Engineering, Zhejiang University, Hangzhou, China; ${ }^{2}$ Cyrus Tang Center for Sensor Materials and Applications, Department of Materials Science and Engineering, Zhejiang University, Hangzhou, China and ${ }^{3}$ Key Laboratory of Advanced Materials and Applications for Batteries of Zhejiang Province, Department of Materials Science and Engineering, Zhejiang University, Hangzhou, China

Correspondence: Professor X-B Zhao or Professor T-J Zhu, State Key Laboratory of Silicon Materials, Department of Materials Science and Engineering, Zhejiang University, 38 Zheda Road, Hangzhou 310027, China.

E-mail: zhaoxb@zju.edu.cn or zhutj@zju.edu.cn

Received 1 August 2013; revised 19 November 2013; accepted 25 November 2013 
However, maximum $Z T$ values are only obtained at room temperature, as rising temperatures dramatically decreased $Z T$ because of intrinsic excitation. ${ }^{4,7,24}$ For low-temperature power generation applications below $500 \mathrm{~K}$, the maximum $Z T$ of $p$-type bismuth telluride-based alloys must be shifted to higher temperatures, employing a composition other than $\mathrm{Bi}_{0.5} \mathrm{Sb}_{1.5} \mathrm{Te}_{3}$. One feasible solution toward the optimization of $Z T$ at elevated temperatures, making them suitable for low-temperature power generation, is to actively suppress intrinsic conduction at elevated temperatures via two strategies. The first is to broaden the band gap; the second is to increase the hole concentration. The origin of hole concentration in p-type $\mathrm{Bi}_{2}{ }_{-\mathrm{x}} \mathrm{Sb}_{\mathrm{x}} \mathrm{Te}_{3}$ mixed crystals is mainly associated with $\mathrm{Sb}_{\mathrm{Te}}^{\prime}$ and $\mathrm{Bi}_{\mathrm{Te}}^{\prime}$ antisite defects, ${ }^{25-27}$ which are created when cations occupy the vacant anion sites during crystal growth from a stoichiometric melt. The formation energy of an antisite defect mainly depends on bond polarity. The lower the polarity of the bonds between cations and anions, the lower the energy for antisite defects. ${ }^{26,27}$ Raising the $\mathrm{Sb}$ content in $\mathrm{Bi}_{2}-\mathrm{x} \mathrm{Sb}_{\mathrm{x}} \mathrm{Te}_{3}$ mixed crystals can reduce the formation energy of antisite defects, thereby increasing the hole concentration because of the smaller difference in electronegativity for $\mathrm{Sb}-\mathrm{Te}$ compared with $\mathrm{Bi}-\mathrm{Te} .{ }^{27}$ The hole concentration may be further tuned through donor-like effects induced during the deformation process by grinding and pressing. ${ }^{22,23,28,29}$ The binary compound $\mathrm{Bi}_{2} \mathrm{Te}_{3}$ has a narrow band gap (approximately $0.13 \mathrm{eV}$ ), ${ }^{30-33}$ which can be adjusted through the formation of solid solutions by alloying with $\mathrm{Sb}_{2} \mathrm{Te}_{3}$ (a larger band gap of approximately $0.28 \mathrm{eV}^{34,35}$ ). ${ }^{36}$ The band gap increases with the addition of $\mathrm{Sb}$ to the rich- $\mathrm{Sb}_{2} \mathrm{Te}_{3}$ region, which can be attributed to increasing degeneracy of charge carriers and the larger band gap of $\mathrm{Sb}_{2} \mathrm{Te}_{3}$ compared with $\mathrm{Bi}_{2} \mathrm{Te}_{3} .{ }^{35}$ Thus, Sb substitution can effectively shift the optimum $Z T$ to higher temperatures. ${ }^{37}$ Nonetheless, systematic work on the effects of Sb-substitution on the TE performance of polycrystalline $\mathrm{Bi}_{2-x} \mathrm{Sb}_{\mathrm{x}} \mathrm{Te}_{3}$ is rare.

In this work, we fabricated a series of $p$-type $\mathrm{Bi}_{2}{ }_{-x} \mathrm{Sb}_{\mathrm{x}} \mathrm{Te}_{3}(x=1.4-$ 1.8) polycrystalline solid solutions by a top-down, HD method to explore the effect of Sb-alloying on the suppression of intrinsic conduction. The optimum $Z T$ was shifted to higher temperatures (approximately $380 \mathrm{~K}$ ) by increasing the values of both band gap and hole concentration. The maximum $Z T$ of 1.3 was attained at $380 \mathrm{~K}$ with the composition $x=1.7$ and TE parameters measured along the same direction. More importantly, the average $Z T_{\mathrm{av}}$ of approximately 1.18 was achieved in the range of $300-480 \mathrm{~K}$, indicating potential for the application of this composition in low-temperature power generation.

\section{EXPERIMENTAL PROCEDURES \\ Melting}

Commercial high-purity elemental chunks of $99.999 \% \mathrm{Bi}, 99.999 \% \mathrm{Sb}$ and 99.999\% Te were used as raw materials. Appropriate quantities of each were weighed according to the nominal composition of $\mathrm{Bi}_{2}{ }_{-} \mathrm{Sb}_{\mathrm{x}} \mathrm{Te}_{3}(x=1.4,1.5$, 1.6, 1.7 and 1.8) and sealed in a quartz tube at $10^{-3} \mathrm{~Pa}$. The element mixture was melted at $1023 \mathrm{~K}$ for $10 \mathrm{~h}$ and cooled in the furnace.

\section{Consolidation of powders and HD}

Ingots were ball milled (MM 200, Retsch Gmbh, Haan, Germany) for 20 min at $15 \mathrm{~Hz}$ to yield fine powders. These powders were hot pressed into cylindrical shapes in a $\phi 10 \mathrm{~mm}$ graphite die at $673 \mathrm{~K}$ for $30 \mathrm{~min}$ under $80 \mathrm{MPa}$. The initial hot-pressed bulk samples with different Sb content $(x)$ were named HP-Sbx. Subsequently, HD was performed by repressing the HP samples in a larger graphite die with an inner diameter of $16 \mathrm{~mm}$ at $823 \mathrm{~K}$ for $30 \mathrm{~min}$ at the same pressure. This HD approach eventually yielded $16 \mathrm{~mm}$ disk-shaped samples, labeled 'HD-Sbx'.

\section{Materials characterization}

The phase identification and grain orientation of all the samples were investigated using X-ray diffraction with a Rigaku D/MAX 2500/PC diffractometer (Rigaku Corp, Tokyo, Japan). In-plane thermal diffusivity $(D)$ was measured on a Netzsch LFA 457 laser flash apparatus (Netzsch Gmbh, Selb, Germany) using the method introduced by Xie et al. ${ }^{38}$ (Supplementary Figure 1a, Supplementary Information). Specific heat $\left(C_{\mathrm{P}}\right)$ was measured on the Netzsch DSC 404C (Netzsch Gmbh) (Supplementary Figure 1b) and density $\left(\rho_{\mathrm{D}}\right)$ was estimated by an ordinary dimension and weight measurement procedure. Thermal conductivity in the in-plane direction was then calculated using the relation $\kappa=D \rho_{\mathrm{D}} C_{\mathrm{P}}$. In-plane electrical conductivity $(\sigma)$ and the Seebeek coefficient $(\alpha)$ were simultaneously measured on a commercial Linseis LSR-3 system (Linseis Gmbh, Selb, Germany). The Hall coefficient $\left(R_{\mathrm{H}}\right)$ was determined at $300 \mathrm{~K}$ on a Quantum Design PPMS-9T instrument using a four-probe configuration (Quantum Design Inc, San Diego, CA, USA). The carrier concentration $\left(n_{\mathrm{H}}\right)$ and in-plane Hall mobility $\left(\mu_{\mathrm{H}}\right)$ were calculated according to $n_{\mathrm{H}}=-1 / e R_{\mathrm{H}}$ (assuming Hall factor of 1.0) and $\mu_{\mathrm{H}}=\sigma R_{\mathrm{H}}$.

\section{RESULTS AND DISCUSSION}

\section{Texture evolution}

Figure 1a shows the in-plane X-ray diffraction patterns of the as-pressed $\mathrm{Bi}_{0.4} \mathrm{Sb}_{1.6} \mathrm{Te}_{3}$ bulk samples before and after HD. All the reflection peaks can be indexed to a rhombohedral phase (JCPDS \#49-1713). The (001) diffraction intensities of the HD sample are much higher than observed the HP samples, revealing the formation of preferred orientation during the HD process. To investigate the texture evolution, the degree of preferred orientation $(F)$ of the (001)planes was calculated by the Lotgering method. ${ }^{39}$ As shown in Figure $1 \mathrm{~b}$, the $\mathrm{F}$ values increase from $0.14-0.17$ in the HP series to $0.20-0.28$ in the HD samples. Obviously, HD causes enhanced texture in the bulk samples because of the occurrence of plastic deformation. In our previous study, a similar process yielded reduced textures, which was ascribed to deformation-induced dynamic recrystallization. ${ }^{7}$ The possible cause of the difference may be the different degree of deformation applied to the samples.

It is well known that both plastic deformation and dynamic recrystallization take place in HD process and have opposite impacts on the degree of texture. The deformation strain $(\varepsilon$, defined by $\varepsilon=\left(H_{0}-H\right) / H_{0}$, where $H_{0}$ and $H$ are the initial thicknesses of the HP samples and the final thicknesses of the HD samples, represents the degree of plastic deformation. A value of $\varepsilon=0.37$ was obtained in the earlier report, ${ }^{7}$ whereas a value of $\varepsilon=0.61$ was observed in this work. The larger deformation strain induced in the present work led to the formation of texture as a result of the comparatively stronger role played by plastic deformation than dynamic recrystallization. The $F$ values reported here are higher than those observed in materials prepared using the MA-spark plasma sintering (MA: mechanical alloying) ${ }^{37}$ or MA-HP ${ }^{40}$ techniques. However, processes such as zone melting accompanied by spark plasma sintering ${ }^{41}$ or shear extrusion $^{42}$ provide stronger textures, with $F$ values of 0.61 (zone melting) and 0.63 (shear extrusion). Scanning Electron Microscopy (SEM) fractographs of the bulk samples give results consistent with X-ray diffraction measurements (Supplementary Figure 2). It should be mentioned that even small degrees of texture will result in large differences between in-plane and out-of-plane thermal conductivities.

\section{Effects of Sb content and HD on TE properties}

In $p$-type $\mathrm{Bi}_{2-\mathrm{x}} \mathrm{Sb}_{\mathrm{x}} \mathrm{Te}_{3}$ alloys, the hole concentration is primarily created by antisite defects in the form of Te sites occupied by Bi or Sb atoms. ${ }^{25-27}$ The incorporation of $\mathrm{Sb}$ atoms into the $\mathrm{Bi}_{2} \mathrm{Te}_{3}$ lattice decreases the difficulty associated with the formation of antisite 
a
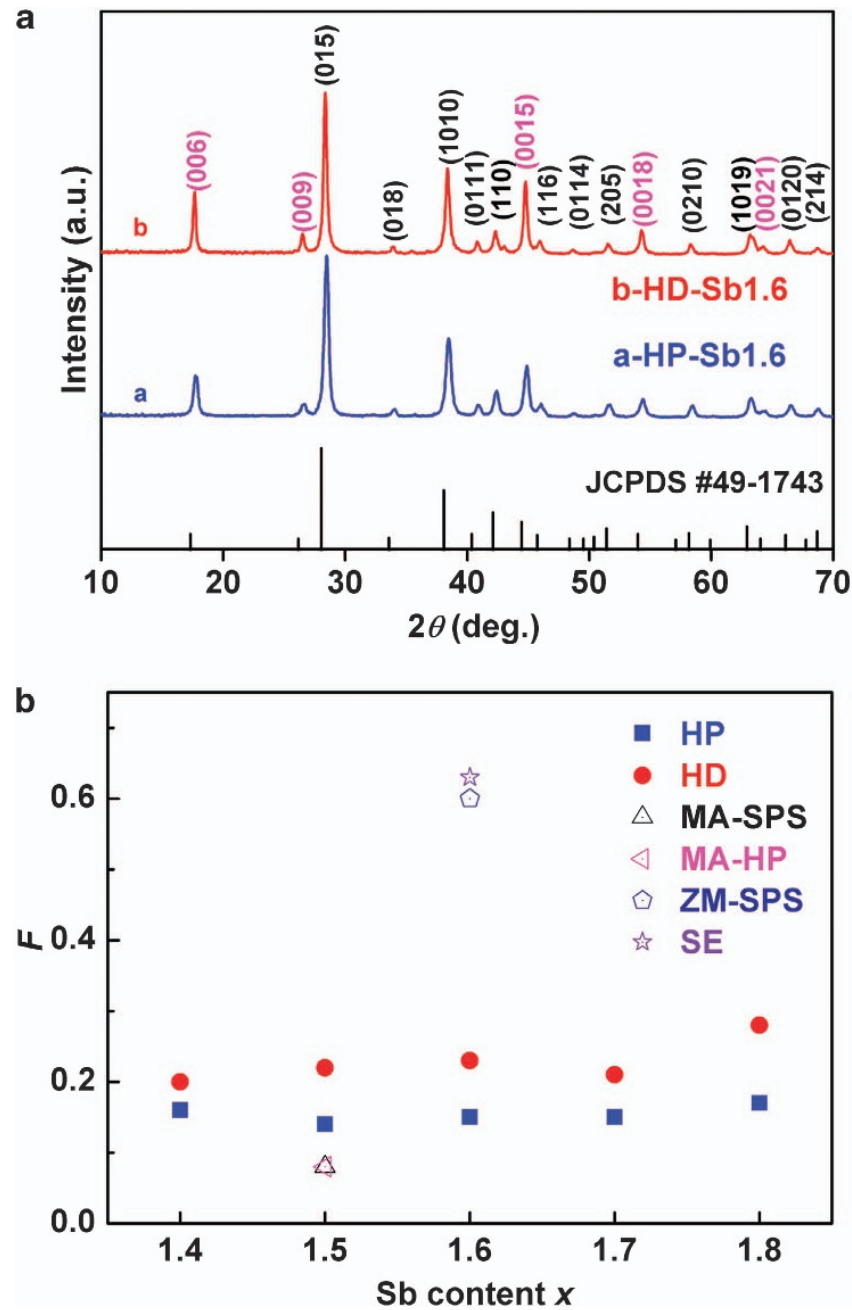

Figure 1 (a) Typical $X$-ray diffraction patterns of the $\mathrm{Bi}_{0.4} \mathrm{Sb}_{1.6} \mathrm{Te}_{3}$ bulk samples before and after hot deformation, measured on the hot pressed surfaces, and (b) $\mathrm{F}$ values of the $\mathrm{Bi}_{2-x} \mathrm{Sb}_{x} \mathrm{Te}_{3}$ bulk samples before and after hot deformation, as well as data from Chen, ${ }^{37}$ Fan, ${ }^{40}$ Jiang $^{41}$ and Kim. ${ }^{42}$
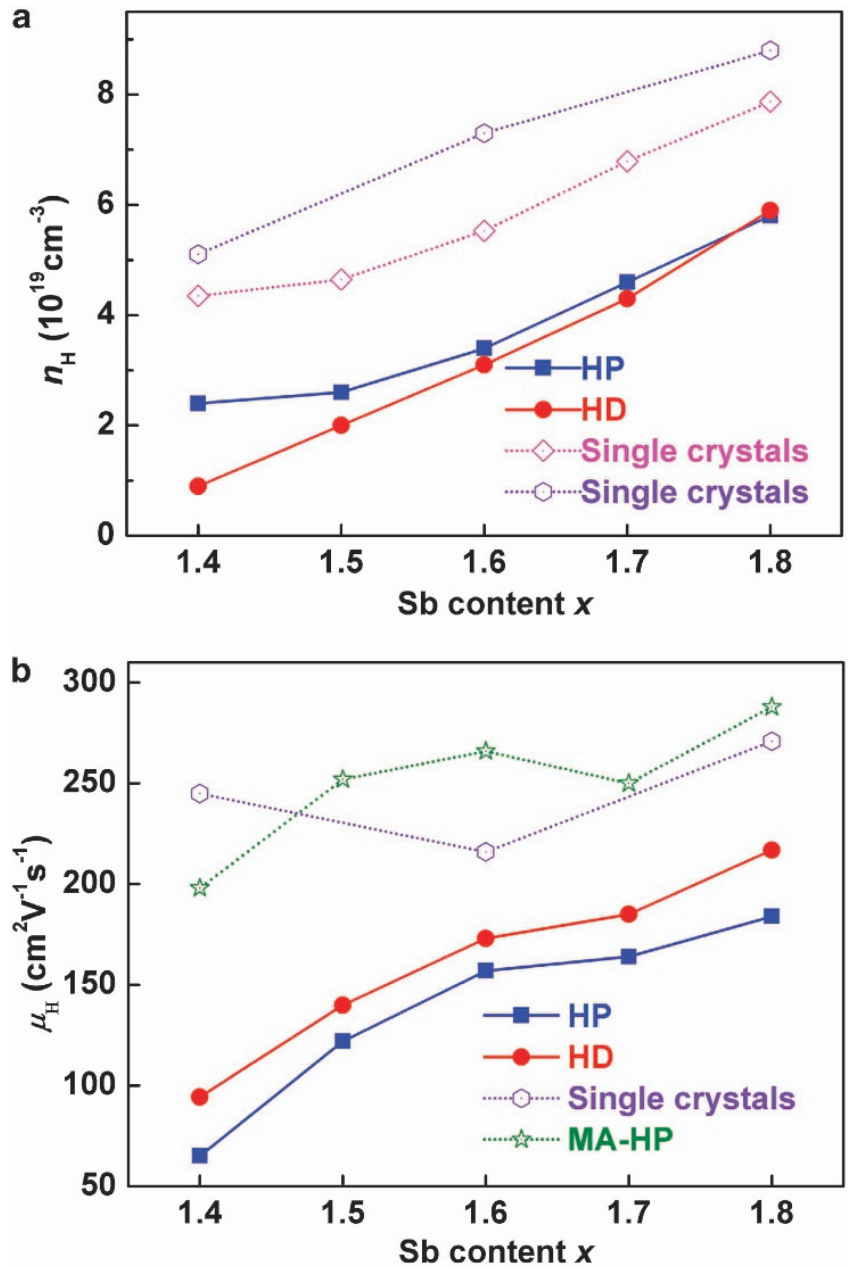

Figure 2 (a) Carrier concentration and (b) in-plane Hall mobility at room temperature as a function of the $\mathrm{Sb}$ content of the $\mathrm{Bi}_{2}{ }_{-x} \mathrm{Sb}_{x} \mathrm{Te}_{3}$ bulk samples before and after hot deformation, as well as data from Stary, ${ }^{27}$ Birkholz ${ }^{43}$ and Fan. ${ }^{48}$ defects and thereby increases the hole concentration. ${ }^{27,43}$ Thus, as illustrated in Figure 2a, the hole concentration $\left(n_{\mathrm{H}}\right)$ monotonically rises with increasing $x$. The $n_{\mathrm{H}}$ values of $\mathrm{Bi}_{2} \mathrm{Te}_{3}$-based alloys are sensitive to both chemical composition and processing-induced lattice defects. $^{22,23,29}$

Tellurium vacancies can be generated by a process of deformationinduced non-basal slip that provides the lattice with excess negative carriers, referred to as the donor-like effect. ${ }^{28,44}$ The donor-like effect can partially compensate for the hole concentration in Sb-rich $p$-type solid solutions. ${ }^{28}$ This phenomenon explains the slight reduction in $n_{\mathrm{H}}$ observed in the HD samples compared with their HP counterparts (Figure 2a). Single crystals prepared by the Bridgeman method without mechanical deformation show the highest $n_{\mathrm{H}}{ }^{27,43}$ The influence of $\mathrm{Sb}$ content on the carrier mobility is illustrated in Figure $2 \mathrm{~b}$. The markedly increased $n_{\mathrm{H}}$ achieved with increasing $x$ leads to strong electron-electron scattering and decreased $\mu_{\mathrm{H}}$. However, it is interesting that both $n_{\mathrm{H}}$ and $\mu_{\mathrm{H}}$ increase with increasing $x$. The increase of $\mu_{\mathrm{H}}$ with increasing $x$ (a reduced $\mathrm{Bi} / \mathrm{Sb}$ ratio) is mainly attributed to weakened alloy scattering, which is consistent with previous studies. ${ }^{24,45}$ In addition, the HD samples show much higher
$\mu_{\mathrm{H}}$ values than the HP samples by virtue of their lower $n_{\mathrm{H}}$ and slightly enhanced textures. ${ }^{22,23,46,47}$ Nevertheless, the measured $\mu_{\mathrm{H}}$ values of the HD samples are still smaller than the $\mu_{\mathrm{H}}$ for the single crystals ${ }^{43}$ and MA-HP ${ }^{48}$ samples of the same composition. Further improvements in $\mu_{\mathrm{H}}$ may be possible through the formation of a highly preferred orientation via repetitive HD or optimization of the process parameters.

The electrical transport properties of the $\mathrm{Bi}_{2}{ }_{-\mathrm{x}} \mathrm{Sb}_{\mathrm{x}} \mathrm{Te}_{3}$ bulk samples have been measured and plotted in Figure 3, wherein a transition from semiconducting $(x=1.4)$ to metal-like $(x>1.5)$ conduction behavior is observed. The remarkable enhancement in $\sigma$ with increasing $\mathrm{x}$ can be attributed to increases in both $n_{\mathrm{H}}$ and $\mu_{\mathrm{H}}$ because of the incremental concentration of antisite defects ${ }^{27,43}$ and reduced alloy scattering, ${ }^{24}$ respectively. Post-HD changes in $\sigma$ were different for materials with $x<1.6$ and $x>1.6$ because of the different magnitudes of the $n_{\mathrm{H}}$ reduction and the $\mu_{\mathrm{H}}$ increase. In particular, $\sigma$ is improved, to some extent, because of texture enhancement in materials with $\mathrm{Sb}$ content $x>1.6$. The electrical conductivities of the $\mathrm{Bi}_{2-\mathrm{X}} \mathrm{Sb}_{\mathrm{x}} \mathrm{Te}_{3} \quad(x=1.5-1.8)$ bulk samples roughly follow a $T^{-1.5}$ dependence near room temperature, indicative of acoustic phonon 

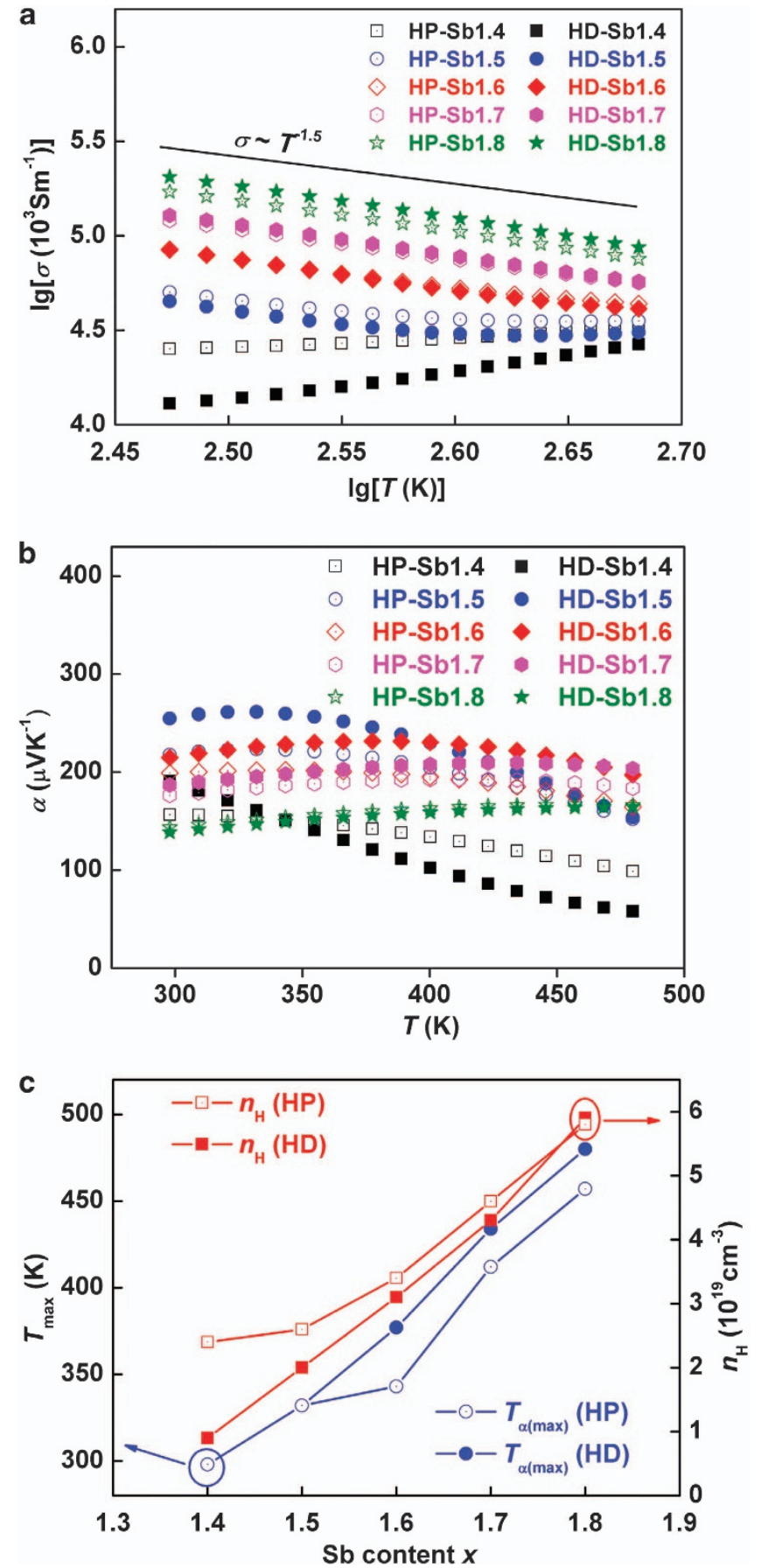

Figure 3 (a) Temperature dependence of electrical conductivity, (b) temperature dependence of Seebeck coefficient and (c) Sb content dependence of temperature for the $\alpha_{\max }$ and $n_{\mathrm{H}}$ of the $\mathrm{Bi}_{2}{ }_{-\mathrm{x}} \mathrm{Sb}_{\mathrm{x}} \mathrm{Te}_{3}$ bulk samples before and after hot deformation.

scattering. The dominant carrier-scattering mechanism does not change after HD processing.

Figure $3 b$ displays the temperature dependence of $\alpha$ for bulk $\mathrm{Bi}_{2}{ }_{\mathrm{x}} \mathrm{Sb}_{\mathrm{x}} \mathrm{Te}_{3}$ samples. Table 1 lists some room temperature physical parameters of the $\mathrm{Bi}_{2-\mathrm{x}} \mathrm{Sb}_{\mathrm{x}} \mathrm{Te}_{3}$ alloys. The reduced Fermi levels $\left(\xi_{\mathrm{F}}\right)$ and carrier effective mass $\left(m^{*}\right)$ were roughly estimated from the measured $\alpha$ and $n_{\mathrm{H}}$ based on a single parabolic band model with acoustic phonon scattering. ${ }^{49}$ Although the calculation using the single parabolic band model may introduce error because of the non-
Table 1 Hole concentration $n_{\mathrm{H}}$, Hall mobility $\mu_{\mathrm{H}}$, Seebeck coefficient $\alpha$, reduced Fermi levels $\xi_{F}$, carrier effective mass $m^{*}$ and sample density $\rho_{\mathrm{D}}$ of the $\mathrm{Bi}_{2-\mathrm{x}} \mathrm{Sb}_{\mathrm{x}} \mathrm{Te}_{3}$ bulk samples at $300 \mathrm{~K}$ before and after hot deformation

\begin{tabular}{|c|c|c|c|c|c|c|}
\hline Samples & $\begin{array}{c}\mathrm{n}_{H} \\
\left(10^{19} \mathrm{~cm}^{-3}\right)\end{array}$ & $\begin{array}{c}\mu_{H} \\
\left(\mathrm{~cm}^{2} V^{-1} \mathrm{~s}^{-1}\right)\end{array}$ & $\alpha\left(\mu V K^{-1}\right)$ & $\xi_{F}$ & $\mathrm{~m} * / \mathrm{m}_{0}$ & $\rho_{D}\left(\mathrm{gcm}^{-3}\right)$ \\
\hline HP-Sb1.4 & 2.4 & 65 & 156 & - & - & 6.82 \\
\hline HD-Sb1.4 & 0.9 & 94 & 191 & - & - & 6.73 \\
\hline HP-Sb1.5 & 2.6 & 122 & 218 & -0.2 & 1.4 & 6.77 \\
\hline HD-Sb1.5 & 2 & 140 & 255 & -0.8 & 1.6 & 6.77 \\
\hline HP-Sb1. 6 & 3.4 & 157 & 199 & 0.1 & 1.4 & 6.71 \\
\hline HD-Sb1.6 & 3.1 & 173 & 215 & -0.2 & 1.5 & 6.65 \\
\hline HP-Sb1.7 & 4.6 & 164 & 176 & 0.5 & 1.4 & 6.67 \\
\hline HD-Sb1.7 & 4.3 & 185 & 187 & 0.3 & 1.5 & 6.44 \\
\hline HP-Sb1.8 & 5.8 & 184 & 144 & 1.2 & 1.2 & 6.72 \\
\hline HD-Sb1.8 & 5.9 & 217 & 139 & 1.3 & 1.2 & 6.57 \\
\hline
\end{tabular}

parabolic nature of the valence band and complex scattering processes, the trends in the values of $\xi_{\mathrm{F}}$ and $m^{*}$ can provide information about the band structure upon the introduction of $\mathrm{Sb}$. The increase in $n_{\mathrm{H}}$ with increasing $x$ is accompanied by a gradual increase in $\xi_{\mathrm{F}}$, indicating the progressive movement of the Fermi level deeper into the valence band. However, the Fermi level slightly shifts toward the valence band edge after HD, as evidenced by the decreased $\xi_{\mathrm{F}}$ of the HD samples in comparison to their HP counterparts. $m^{\star}$ remains nearly unchanged with increasing $x$. The slight decrease in $m^{\star}$ at $x=1.8$ can be attributed to variations in the valence band constituents, consistent with Stordeur's results. ${ }^{50}$ Deformation does not cause changes in $m^{*}$.

The room temperature value of $\alpha$ is reduced from $255 \mu \mathrm{VK}^{-1}$ (HD-Sb1.5) to $139 \mu \mathrm{VK}^{-1}$ (HD-Sb1.8) with increasing $x$, because of the increase in $n_{\mathrm{H}}$. The noticeable improvement in $\alpha$ achieved after $\mathrm{HD}$ is a result of the reduction in $n_{\mathrm{H}}$. Therefore, HD processing enables the improvement of $\alpha$ through $n_{\mathrm{H}}$ reduction, whereas slightly increasing $\sigma$ by enhancing the textures of the $\mathrm{Bi}_{0.3} \mathrm{Sb}_{1.7} \mathrm{Te}_{3}$ samples. The band gaps of the hot-deformed $\mathrm{Bi}_{2}{ }_{-x} \mathrm{Sb}_{\mathrm{x}} \mathrm{Te}_{3}(x=1.4-1.7)$ bulk samples were roughly estimated using the relationship between the peak $\alpha$ and the corresponding temperature, that is, $E_{\mathrm{g}}=2 e \alpha_{\max } T_{\max }$. Slight band gap enhancement was observed from $x=1.4\left(E_{\mathrm{g}}=0.11\right.$ $\mathrm{eV})$ to $x=1.7\left(E_{\mathrm{g}}=0.18 \mathrm{eV}\right)$. The behaviors of $T_{\max }$ and $n_{\mathrm{H}}$ as functions of $x$ are also shown in Figure 3c. It is clear that the temperature at which $\alpha_{\max }$ is observed gradually rises as the $\mathrm{Sb}$ content increases from 1.4 to 1.8 because of the suppression of the detrimental effects of minority carriers on $\alpha$.

A plot of the calculated power factors $P F=\sigma \alpha^{2}$ is shown in Figure 4. The value of $P F$ increases considerably with increasing $x$, because of a substantial improvement in $\sigma$. All the HD samples exhibit higher $P F$ values than their HP counterparts, except when $x=1.4$. A maximum value of $4.5 \times 10^{-3} \mathrm{Wm}^{-1} \mathrm{~K}^{-2}$ was achieved at room temperature for the HD-Sb1.7 sample, approximately $20 \%$ higher than without HD.

In-plane thermal conductivity was measured using the method introduced by Xie et al. ${ }^{38}$ The variation of in-plane $\kappa$ with temperature is plotted in Figure $5 \mathrm{a}$. The rise of $\kappa$ at room temperature with increasing $x$ is mainly ascribed to an increase in the electronic contribution $\kappa_{\mathrm{e}}$, which is estimated by the Wiedeman-Franz relationship $\left(\kappa_{\mathrm{el}}=\mathrm{L}_{0} \sigma \mathrm{T}\right)$ using the Lorentz constant, $\mathrm{L}_{0}$, of $2.0 \times 10^{-8}$ $\mathrm{V}^{2} \mathrm{~K}^{-2}$. The value of $\kappa_{\mathrm{el}}$ calculated at $298 \mathrm{~K}$ for the HD-Sb1.4 


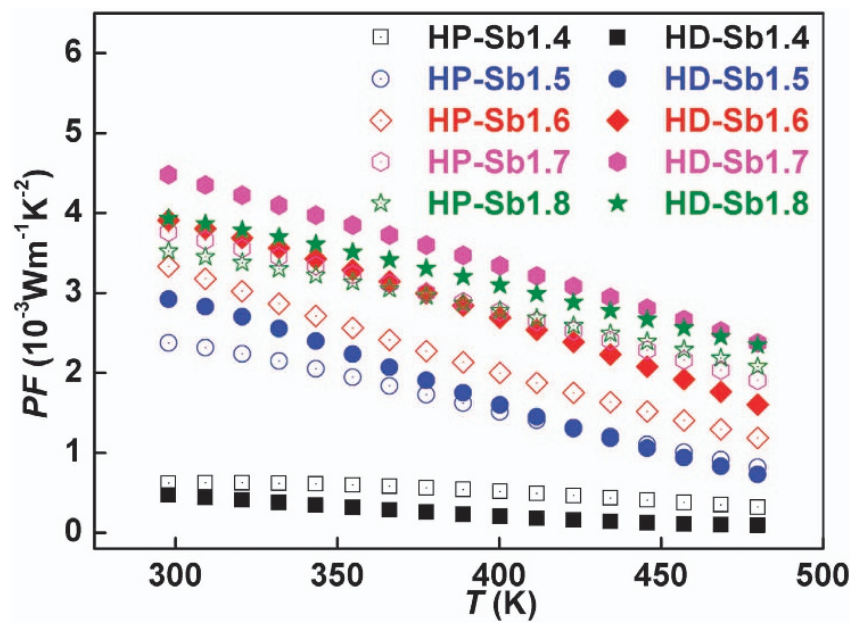

Figure 4 Temperature dependences of the power factor, $P F$, of the $\mathrm{Bi}_{2}{ }_{-x} \mathrm{Sb}_{x} \mathrm{Te}_{3}$ bulk samples before and after hot deformation.
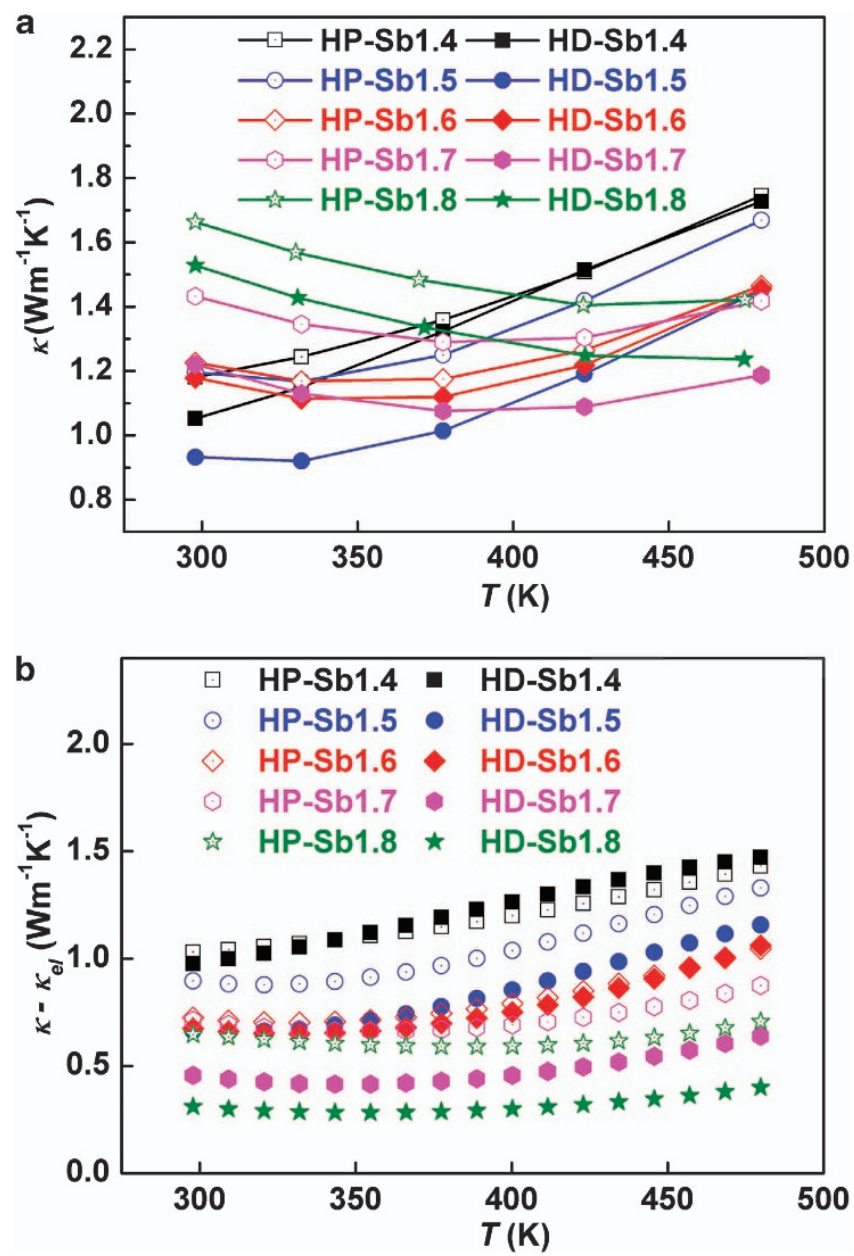

Figure 5 Temperature dependences of the in-plane (a) total thermal conductivity and (b) lattice thermal conductivity of the $\mathrm{Bi}_{2-x} \mathrm{Sb}_{x} \mathrm{Te}_{3}$ bulk samples before and after hot deformation.

sample is $0.08 \mathrm{Wm}^{-1} \mathrm{~K}^{-1}$. This value increases to $1.22 \mathrm{Wm}^{-1} \mathrm{~K}^{-1}$ for the HD-Sb1.8 sample. The value of $\kappa_{\mathrm{ph}}$, approximately equal to $\kappa-\kappa_{\mathrm{el}}$ before the intrinsic excitation, is plotted as a function of temperature in Figure 5b. The HD samples have enhanced (001)
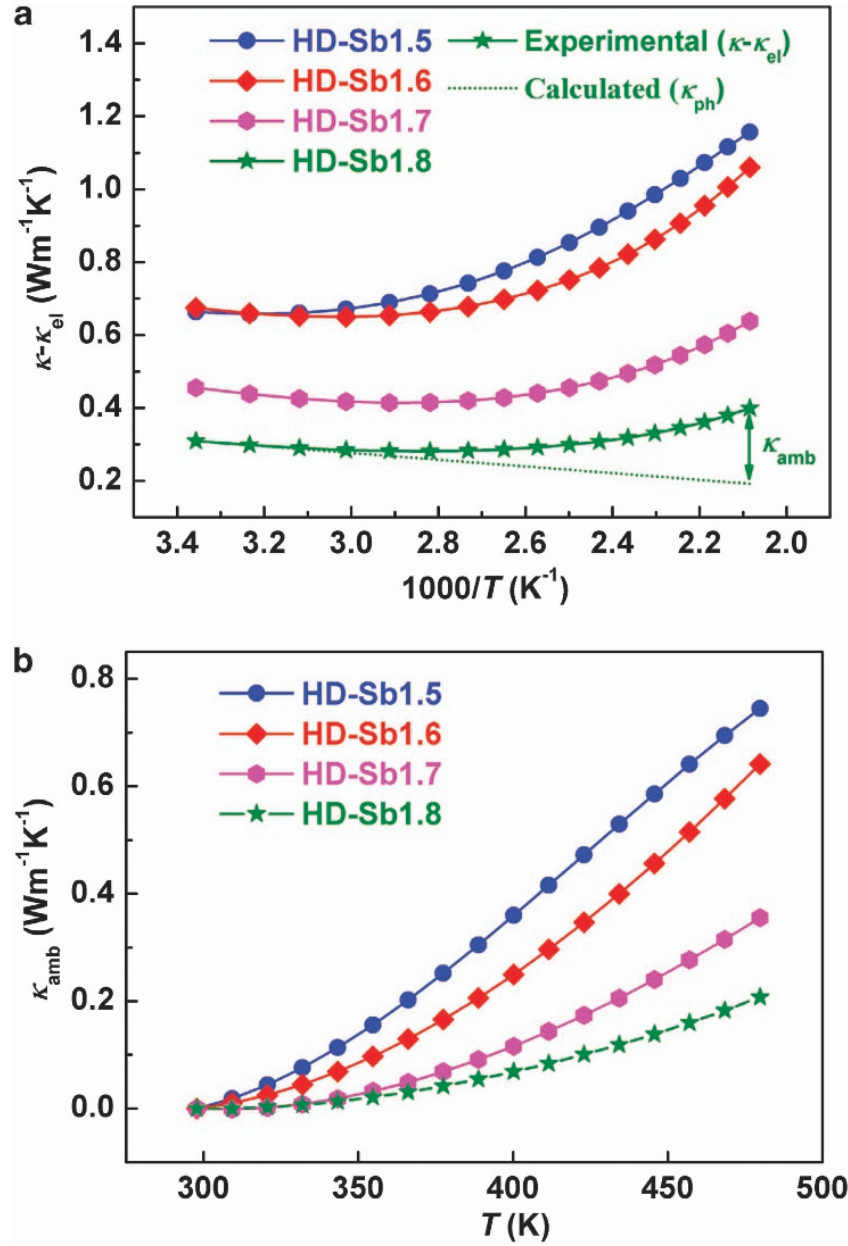

Figure 6 Temperature dependences of (a) the calculated lattice thermal conductivity and (b) ambipolar thermal conductivity of the hot-deformed $\mathrm{Bi}_{2-x} \mathrm{Sb}_{\mathrm{x}} \mathrm{Te}_{3}$ bulk samples.

texture; therefore, higher in-plane $\kappa$ values are generally expected. However, the HD samples have lower values of $\kappa$ when compared with their HP counterparts, likely as a result of enhanced phonon scattering by local nanostructures and high-density lattice defects created by HD processing, as demonstrated earlier. ${ }^{7,21-23}$ In particular, the extremely low $\kappa_{\mathrm{ph}}$ obtained for the HD-Sb1.8 sample $\left(0.28 \mathrm{Wm}^{-1} \mathrm{~K}^{-1}\right)$ at $355 \mathrm{~K}$ is only approximately $45 \%$ of that for its HP counterpart.

Suppression of ambipolar thermal conductivity

Within the intrinsic conduction region, there is an additional component to the thermal conductivity arising from the diffusion of electron-hole pairs, called the ambipolar component $\kappa_{\mathrm{amb}}$. Sizeable values of $\kappa_{\mathrm{amb}}$ have serious adverse effects on the $\kappa$, which are particularly notable in the samples with low Sb content. We evaluated $\kappa_{\mathrm{amb}}$ for the materials presented in this work to compare the ambipolar contribution to $\kappa$ for alloys of different Sb content. In cases where $\kappa_{\mathrm{amb}}$ has no role, the relationship between the $\kappa_{\mathrm{ph}}$ and the reciprocal of temperature $(1 / T)$ is theoretically linear $\left(\kappa_{\mathrm{ph}} \propto 1 / T\right)$. Assuming a negligible effect of $\kappa_{\mathrm{amb}}$ on $\kappa$ before intrinsic excitation, the difference between the calculated $\kappa_{\mathrm{ph}}$ and experimental $\kappa-\kappa_{\mathrm{el}}$ is approximately equal to $\kappa_{\mathrm{amb}}$ (Figure 6a). The value of $\kappa_{\mathrm{amb}}$ increases with temperature, but the magnitude of the increase reduces with increasing $x$. This may be ascribed to the suppression of intrinsic 


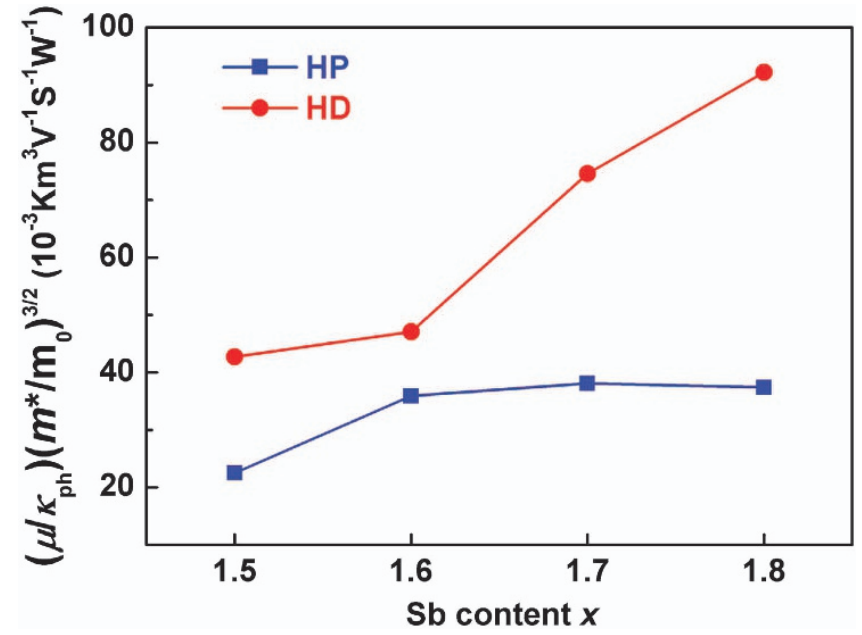

Figure $7\left(\mu / \kappa_{\mathrm{ph}}\right)\left(m^{\star} / m_{0}\right)^{3 / 2}$ as a function of the Sb content, $\boldsymbol{x}$, at $300 \mathrm{~K}$.
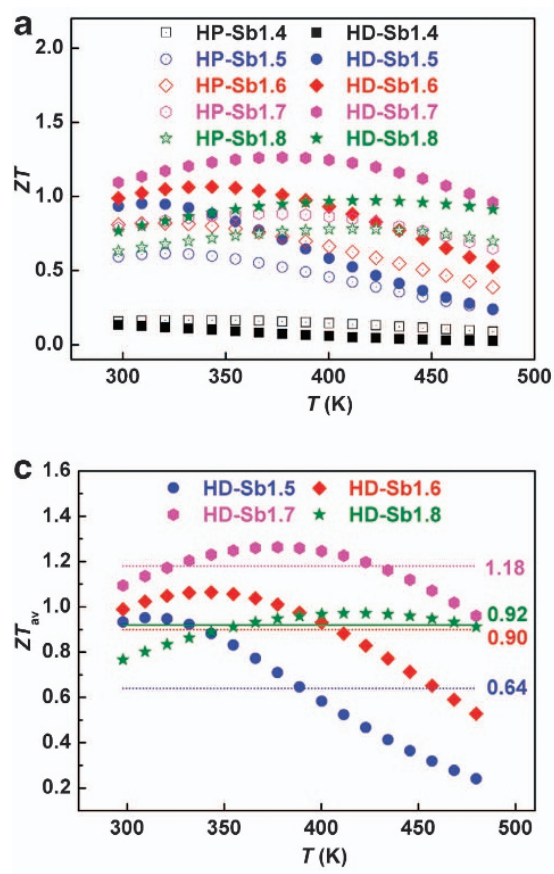

conduction by increases in both the hole concentration and band gap (Figure $6 \mathrm{~b}$ ). For example, the $\kappa_{\mathrm{amb}}$ value calculated at $400 \mathrm{~K}$ for the HD-Sb1.5 sample is $0.36 \mathrm{Wm}^{-1} \mathrm{~K}^{-1}$, but it is only $0.07 \mathrm{Wm}^{-1} \mathrm{~K}^{-1}$ for the HD-Sb1.8 sample. This approximate $80 \%$ reduction indicates that the detrimental effects of intrinsic conduction are substantially suppressed by increased Sb content.

The materials parameter $\beta$ and dimensionless figure of merit $Z T$ The materials parameter $(\beta$, Figure 7$)$ is proportional to $\left(\mu / \kappa_{\mathrm{ph}}\right)$ $\left(m^{*} / m_{0}\right)^{3 / 2}$ and determines the TE efficiency. ${ }^{51}$ Enhancing TE performance requires an increased ratio of carrier mobility to lattice thermal conductivity, along with a high effective mass. Obviously, the value of $\left(\mu / \kappa_{\mathrm{ph}}\right)\left(m^{*} / m_{0}\right)^{3 / 2}$ at $300 \mathrm{~K}$ rises with increasing Sb content in our bulk polycrystalline samples. HD remarkably improves $\beta$, showing its promise as a preparation technique for high performance TE materials.

The dimensionless figure of merit, with both electrical and thermal properties measured along the in-plane direction as a function

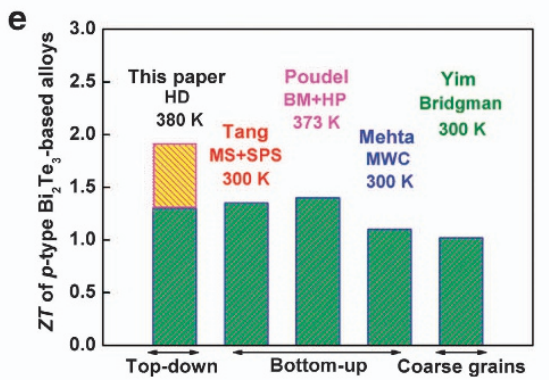

Figure 8 (a) Temperature dependences of $Z T$ values, (b) $Z T$ values at 300 and $380 \mathrm{~K}$ as a function of Sb content $x$, as well as data from Ivanova, ${ }^{53} \mathrm{Yim},{ }^{24}$ Fan. ${ }^{48}$ (c) Average $Z T_{\text {av }}$ values of the hot-deformed $\mathrm{Bi}_{2-x} \mathrm{Sb}_{x} \mathrm{Te}_{3}$ bulk samples, (d) $Z \mathrm{~T}$ values of the $\mathrm{Bi}_{0.3} \mathrm{Sb}_{1.7} \mathrm{Te}_{3}$ samples prepared several times to demonstrate processing repeatability, and (e) the maximum ZT value compared with some other typical work using the traditional composition $\mathrm{Bi}_{0.5} \mathrm{Sb}_{1.5} \mathrm{Te}_{3}{ }^{4,6,8,24}$ (The yellow-shadowed part indicates the overvalued $Z T$ determined by in-plane $\sigma$ and out-of-plane $\kappa$.). 
of temperature, is calculated and displayed in Figure 8a. Considerable enhancement in $Z T$ was obtained via raising $x$, especially at elevated temperatures. Deformation process further optimizes the ZT. The Sb-rich HD-Sb1.7 sample shows the highest ZT (approximately 1.3 ) at $380 \mathrm{~K}$, almost $45 \%$ better than its HP counterpart, indicating its suitability for low-temperature power generation. Traditional $\mathrm{Bi}_{0.5} \mathrm{Sb}_{1.5} \mathrm{Te}_{3}$ alloys grown by zone melting display a maximum ZT of approximately 1 and optimal hole concentrations near room temperature. ${ }^{24,52}$ These values are greatly reduced by the donor-like effects induced by ball milling and $\mathrm{HD}$, so the optimum composition of the polycrystalline bulk samples for power generation at higher temperatures will be richer in $\mathrm{Sb}$ (Figure $8 \mathrm{~b}$ ).

Owing to the gradual increases in the band gap and hole concentration with increasing $\mathrm{Sb}$ content, the temperature of the maximum $Z T$ shifts gradually to higher temperatures as a result of the suppression of intrinsic conduction. More importantly, there is a significant improvement in the average $Z T_{\mathrm{av}}$ value throughout the temperature range studied. The average $Z T_{\mathrm{av}}$ value for the HD-Sb1.7 sample is 1.18 (Figure 8c). To corroborate the present results, an HD $\mathrm{Bi}_{0.3} \mathrm{Sb}_{1.7} \mathrm{Te}_{3}$ sample was re-prepared twice using the same procedure. Highly repeatable, excellent $Z T$ values (1.26-1.32) were obtained (Figure $8 \mathrm{~d}$ ). The maximum $Z T$ in this work is higher than values for samples prepared by a microwave-stimulated wet-chemical method $(Z T=1.1)^{8}$ or the Bridgman technique $(Z T=1.0),{ }^{24}$ and is comparable to a value achieved with a bottom-up ball milling approach $(Z T=1.4),{ }^{6}$ as shown in Figure 8e. Li et al. ${ }^{53}$ also reported a high $Z T$ (approximately 1.33 ) at $373 \mathrm{~K}$ for ball-milled $\mathrm{Bi}_{0.3} \mathrm{Sb}_{1.7} \mathrm{Te}_{3}$ alloys with $\mathrm{SiC}$ nanoparticles but not for $\mathrm{Bi}_{0.5} \mathrm{Sb}_{1.5} \mathrm{Te}_{3}$. It is also worth noting that the use of both the in-plane $\sigma$ and out-ofplane $\kappa$ to determine the $Z T$ would lead to an overvalued figure of 1.9 (the shadow part in Figure 8e), despite its weak texture. However, property anisotropies were neither mentioned nor discussed in detail for the high $Z T$ values reported in previous studies. ${ }^{4,6,8}$

In summary, we successfully shifted the maximum $Z T$ values of p-type bismuth telluride-based alloys to relatively high temperatures (approximately $380 \mathrm{~K}$ ) by Sb-alloying. The detrimental effects of minority carriers on the Seebeck coefficient and thermal conductivity were suppressed as a result of increases in both the hole concentration and band gap. High-performance bismuth telluride-based alloys were fabricated utilizing the HD method. The formation of preferred orientation during the HD process is beneficial to the improvement of electrical conductivity. A donor-like effect partially compensated for the hole concentration, increasing the Seebeck coefficient. Aside from this, the lattice thermal conductivity was considerably reduced by the presence of recrystallization-induced in situ nanostructures and highdensity lattice defects. As a consequence of these factors, the hotdeformed $\mathrm{Bi}_{0.3} \mathrm{Sb}_{1.7} \mathrm{Te}_{3}$ alloy, rather than the typical $\mathrm{Bi}_{0.5} \mathrm{Sb}_{1.5} \mathrm{Te}_{3}$ composition, showed a maximum $Z T$ of 1.3 at $380 \mathrm{~K}$ and the largest average $Z T_{\mathrm{av}}$ of 1.18 in the range of $300-480 \mathrm{~K}$. These data indicate significant promise for these materials in low-temperature power generation. As these results proved extremely reproducible, this is a promising approach for the mass production of high-performance TE materials.

\section{ACKNOWLEDGEMENTS}

The work was supported by the National Basic Research Program of China (2013CB632503), the Nature Science Foundation of China (51061120455 and 51271165), the PhD program of the Foundation of the Ministry of Education of China (Nos. 20120101110082 and 20110101110024) and the Program for New Century Excellent Talents in University (NCET-12-0495).
1 DiSalvo, F. J. Thermoelectric cooling and power generation. Science 285, 703-706 (1999).

2 Zhao, X. B., Ji, X. H., Zhang, Y. H., Zhu, T. J., Tu, J. P. \& Zhang, X. B. Bismuth telluride nanotubes and the effects on the thermoelectric properties of nanotube-containing nanocomposites. Appl. Phys. Lett. 86, 062111 (2005).

3 Dresselhaus, M. S., Chen, G., Tang, M. Y., Yang, R. G., Lee, H., Wang, D. Z., Ren, Z. F. Fleurial, J. P. \& Gogna, P. New directions for low-dimensional thermoelectric materials. Adv. Mater. 19, 1043-1053 (2007)

4 Tang, X. F., Xie, W. J., Li, H., Zhao, W. Y., Zhang, Q. J. \& Niino, M. Preparation and thermoelectric transport properties of high-performance p-type Bi2Te3 with layered nanostructure. Appl. Phys. Lett. 90, 012102 (2007).

5 Cao, Y. Q., Zhao, X. B., Zhu, T. J., Zhang, X. B. \& Tu, J. P. Syntheses and thermoelectric properties of $\mathrm{Bi} 2 \mathrm{Te} 3 / \mathrm{Sb} 2 \mathrm{Te} 3$ bulk nanocomposites with laminated nanostructure. Appl. Phys. Lett. 92, 143106 (2008).

6 Poudel, B., Hao, Q., Ma, Y., Lan, Y. C., Minnich, A., Yu, B., Yan, X., Wang, D. Z., Muto, A., Vashaee, D., Chen, X. Y., Liu, J. M., Dresselhaus, M. S., Chen, G. \& Ren, Z. F. High-thermoelectric performance of nanostructured bismuth antimony telluride bulk alloys. Science 320, 634-638 (2008).

7 Shen, J. J., Zhu, T. J., Zhao, X. B., Zhang, S. N., Yang, S. H. \& Yin, Z. Z. Recrystallization induced in situ nanostructures in bulk bismuth antimony tellurides: a simple top down route and improved thermoelectric properties. Energy Environ. Sci. 3, 1519-1523 (2010).

8 Mehta, R. J., Zhang, Y. L., Karthik, C., Singh, B., Siegel, R. W., Tasciuc, T. B. \& Ramanath, G. A new class of doped nanobulk high-figure-of-merit thermoelectrics by scalable bottom-up assembly. Nature Mater. 11, 233-240 (2012).

9 Li, J. F., Liu, W. S., Zhao, L. D. \& Zhou, M. High-performance nanostructured thermoelectric materials. NPG Asia Mater 2, 152-158 (2010).

10 Heremans, J. P., Jovovic, V., Toberer, E. S., Saramat, A., Kurosaki, K., Charoenphakdee, A., Yamanaka, S. \& Snyder, G. J. Enhancement of thermoelectric efficiency in PbTe by distortion of the electronic density of states. Science 321, 554-557 (2008).

11 Pei, Y., Shi, X., LaLonde, A., Wang, H., Chen, L. \& Snyder, G. J. Convergence of electronic bands for high performance bulk thermoelectrics. Nature 473, 66-69 (2011).

12 Pei, Y. Z., Wang, H., Gibbs, Z. M., LaLonde, A. D. \& Snyder, J. G. Thermopower enhancement in $\mathrm{Pb}_{1-\mathrm{x}} \mathrm{Mn}_{\mathrm{x}} \mathrm{Te}$ alloys and its effect on thermoelectric efficiency. NPG Asia Mater. 4, e28 (2012)

13 Liu, W., Tan, X. J., Yin, K., Liu, H. J., Tang, X. F., Shi, J., Zhang, Q. J. \& Uher, C. Convergence of conduction bands as a means of enhancing thermoelectric performance of $\mathrm{n}$-type $\mathrm{Mg}_{2} \mathrm{Si}_{1}-{ }_{x} \mathrm{Sn}_{\mathrm{x}}$ solid solutions. Phys. Rev. Lett. 108, 166601 (2012).

14 Zhang, Q., Cao, F., Liu, W. S., Lucas, K., Yu, B., Chen, S., Opeil, C., Broido, D., Chen, G. \& Ren, Z. F. Heavy doping and band engineering by potassium to improve the thermoelectric figure of merit in p-type $\mathrm{PbTe}, \mathrm{PbSe}$, and $\mathrm{PbTe}_{1-y} \mathrm{Se}_{\mathrm{y}}$. J. Am. Chem. Soc 134, 10031-10038 (2012).

15 Jiang, J., Chen, L. D., Yao, Q., Bai, S. Q. \& Wang, Q. Effect of Tel4 content on the thermoelectric properties of n-type $\mathrm{Bi}$-Te-Se crystals prepared by zone melting. Mater. Chem. Phys. 92, 39-42 (2005).

16 Yamashita, O., Tomiyoshi, S. \& Makita, K. J. Bismuth telluride compounds with high thermoelectric figures of merit. Appl. Phys. 93, 368-374 (2003).

17 Zemskov, V. S., Belaya, A. D., Beluy, U. S. \& Kozhemyakin, G. N. J. Growth and investigation of thermoelectric properties of Bi-Sb alloy single crystals. Cryst. Growth 212, 161-166 (2000).

$18 \mathrm{Ma}$, Y., Hao, Q., Poudel, B., Lan, Y. C., Yu, B., Wang, D. Z., Chen, G. \& Ren, Z. F. Enhanced thermoelectric figure-of-merit in p-type nanostructured bismuth antimony tellurium slloys made from elemental chunks. Nano Lett. 8, 2580-2584 (2008).

19 Liu, W. S., Lucas, K. C., McEnaney, K., Li, S., Zhang, Q., Opeil, C. P., Chen, G. \& Ren, Z. F. Studies on the $\mathrm{Bi}_{2} \mathrm{Te}_{3}-\mathrm{Bi}_{2} \mathrm{Se}_{3}-\mathrm{Bi}_{2} \mathrm{~S}_{3}$ system for mid-temperature thermoelectric energy conversion. Energy Environ. Sci. 6, 552-560 (2013).

20 Xie, W. J., Tang, X. F., Yan, Y. G., Zhang, Q. J. \& Tritt, T. M. Unique nanostructures and enhanced thermoelectric performance of melt-spun BiSbTe alloys. Appl. Phys. Lett 94, 102111 (2009).

21 Shen, J. J., Yin, Z. Z., Yang, S. H., Yu, C., Zhu, T. J. \& Zhao, X. B. Improved thermoelectric performance of p-type bismuth antimony telluride bulk alloys prepared by Hot Forging. J. Electron. Mater. 40, 1095-1099 (2011).

$22 \mathrm{Hu}$, L. P., Gao, H. L., Liu, X. H., Xie, H. H., Shen, J. J., Zhu, T. J. \& Zhao, X. B. Enhancement in thermoelectric performance of bismuth telluride based alloys by multi-scale microstructural effects. J. Mater. Chem. 22, 16484-16490 (2012).

$23 \mathrm{Hu}$, L. P., Liu, X. H., Xie, H. H., Shen, J. J., Zhu, T. J. \& Zhao, X. B. Improving thermoelectric properties of n-type bismuth-telluride-based alloys by deformationinduced lattice defects and texture enhancement. Acta Mater. 60, 4431-4437 (2012).

24 Yim, W. M. \& Rosi, F. D. Compound tellurides and their alloys for peltier cooling. SolidState Electron. 15, 1121-1140 (1972).

25 Miller, G. R. \& Li, C. Y. Evidence for the existence of antistructure defects in bismuth telluride by density measurements. J. Phys. Chem. Solids 26, 173-177 (1965).

26 Horak, J., Cermak, K. \& Koudelka, L. Energy formation of antisite defects in doped Sb2Te3 and Bi2Te3 crystals. J. Phys. Chem. Solids 47, 805-809 (1986).

27 Stary, Z., Horak, J., Stordeur, M. \& Stolzer, M. Antisite defects in $\mathrm{Sb}_{2-x} \mathrm{Bi}_{x} \mathrm{Te}_{3}$ mixed crystals. J. Phys. Chem. Solids 49, 29-34 (1988).

28 Navratil, J., Stary, Z. \& Plechacek, T. Thermoelectric properties of p-type antimony bismuth telluride alloys prepared by cold pressing. Mater. Res. Bull 31, 1559-1566 (1996). 
29 Oh, T. S., Hyun, D. B. \& Kolomoets, N. V. Thermoelectric properties of the hot-pressed $(\mathrm{Bi}, \mathrm{Sb})_{2}(\mathrm{Te}, \mathrm{Se})_{3}$ alloys. Scripta Mater. 42, 849-854 (2000)

30 Austin, I. G. The optical properties of bismuth telluride. Proc. Phys. Soc. Lond. 72, 545-552 (1958).

31 Black, J., Conwell, E. M., Seigle, L. \& Spencer, C. W. Electrical and optical properties of some $\mathrm{M}_{2} \mathrm{~V}-\mathrm{B} \mathrm{N}_{3} \mathrm{VI}-\mathrm{B}$ semiconductors. J. Phys. Chem. Solids 2, 240-251 (1957).

32 Kohler, $\mathrm{H}$. Non-parabolicity of highest valence band of $\mathrm{Bi}_{2} \mathrm{Te}_{3}$ from Shubnikov-Dehaas effect. Phys. Status. Solidi. B 74, 591-600 (1976).

33 Kohler, $\mathrm{H}$. Non-parabplic $\mathrm{E}(\mathrm{K})$ relation of lowest conduction-band in $\mathrm{Bi}_{2} \mathrm{Te}_{3}$. Phys. Status Solidi. B 73, 95-104 (1976).

34 Langhammer, H. T., Stordeur, M., Sobotta, H. \& Riede, V. Ir transmission investigations of $\mathrm{Sb}_{2} \mathrm{Te}_{3}$ single-crystals. Phys. Status Solidi. B 123, K47-K51 (1984).

35 Sehr, R. \& Testardi, L. R. Optical properties of p-type $\mathrm{Bi}_{2} \mathrm{Te}_{3}-\mathrm{Sb}_{2} \mathrm{Te}_{3}$ alloys between 2 15 microns. J. Phys. Chem. Solids 23, 1219-1224 (1962).

36 Smith, M. J., Knight, R. J. \& Spencer, C. W. Properties of $\mathrm{Bi}_{2} \mathrm{Te}_{3}-\mathrm{Sb}_{2} \mathrm{Te}_{3}$ alloys. J. Appl. Phys. 33, 2186-2190 (1962).

37 Chen, C., Liu, D. W., Zhang, B. P. \& Li, J. F. Enhanced thermoelectric properties obtained by compositional pptimization in p-type $\mathrm{Bi}_{x} \mathrm{Sb}_{2-x} \mathrm{Te}_{3}$ fabricated by mechanical alloying and spark plasma sintering. J. Electron. Mater 40, 942-947 (2011).

38 Xie, W. J., He, J., Zhu, S., Holgate, T., Wang, S. Y., Tang, X. F., Zhang, Q. J. \& Tritt, T. M. J. Investigation of the sintering pressure and thermal conductivity anisotropy of melt-spun spark-plasma-sintered $(\mathrm{Bi}, \mathrm{Sb})_{2} \mathrm{Te}_{3}$ thermoelectric materials. Mater. Res. 26 1791-1799 (2011)

39 Lotgering, F. K. Topotactical reactions with ferromagnetic oxides having hexagonal crystal structures. J. Inorg. Nucl. Chem. 9, 113-123 (1959).

40 Fan, X. A., Yang, J. Y., Chen, R. G., Zhu, W. \& Bao, S. Q. Phase transformation and thermoelectric properties of p-type $\left(\mathrm{Bi}_{2} \mathrm{Te}_{3}\right)_{(0.25)}\left(\mathrm{Sb}_{2} \mathrm{Te}_{3}\right)_{(0.75)}$ prepared by mechanical alloying and hot pressing. Mater. Sci. Eng. 438, 190-193 (2006).

41 Jiang, J., Chen, L. D., Bai, S. Q. \& Yao, Q. Thermoelectric performance of p-type Bi$\mathrm{Sb}-\mathrm{Te}$ materials prepared by spark plasma sintering. J. Alloy Compd 390, 208-211 (2005).

$42 \mathrm{Kim}, \mathrm{S}$. S. \& Aizawa, T. Thermoelectric properties for p-type $\left(\mathrm{Bi}_{2} \mathrm{Te}_{3}\right)_{(0.2)}\left(\mathrm{Sb}_{2} \mathrm{Te}_{3}\right)_{(0.8)}$ alloys fabricated by shear extrusion. Met. Mater. Int. 12, 317-322 (2006).

43 Birkholz, U. Untersuchung der intermetallischen verbindung $\mathrm{Bi}_{2} \mathrm{Te}_{3}$ sowie der festen losungen $\mathrm{Bi}_{2-x} \mathrm{Sb}_{x} \mathrm{Te}_{3}$ und $\mathrm{Bi}_{2} \mathrm{Te}_{3-}{ }_{-} \mathrm{Se}_{x}$ hinsichtlich ihrer eignung als material fur halbleiter-thermoelemente. Z. Phys. Chem. 13, 780-792 (1958).
44 Schultz, J. M., Tiller, W. A. \& McHugh, J. P. Effects of heavy deformation and annealing on the electrical properties of $\mathrm{Bi}_{2} \mathrm{Te}_{3}$. J. Appl. Phys. 33, 2443-2450 (1962).

45 Yim, W. M., Fitzke, E. V. \& Rosi, F. D. Thermoelectric properties of $\mathrm{Bi}_{2} \mathrm{Te}_{3}-\mathrm{Sb}_{2} \mathrm{Te}_{3}$ $\mathrm{Sb}_{2} \mathrm{Se}_{3}$ pseudo-ternary alloys in the temperature range 77 to 300 K. J. Mater. Sci. 1 , 52-65 (1966).

46 Zhao, L. D., Zhang, B. P., Li, J. F., Zhang, H. L. \& Liu, W. S. Enhanced thermoelectric and mechanical properties in textured n-type $\mathrm{Bi}_{2} \mathrm{Te}_{3}$ prepared by spark plasma sintering. Solid State Sci. 10, 651-658 (2008).

47 Yan, X., Poudel, B., Ma, Y., Liu, W. S., Joshi, G., Wang, H., Lan, Y. C., Wang, D. Z., Chen, G. \& Ren, Z. F. Experimental studies on anisotropic thermoelectric properties and structures of $n$-type $\mathrm{Bi}_{2} \mathrm{Te}_{2.7} \mathrm{Se}_{0.3}$. Nano Lett. 10, 3373-3378 (2010).

48 Fan, X. A., Yang, J. Y., Zhu, W., Bao, S. Q., Duan, X. K., Xiao, C. J., Zhang, Q. Q. \& Xie, Z. J. Effect of nominal $\mathrm{Sb}_{2} \mathrm{Te}_{3}$ content on thermoelectric properties of $\mathrm{p}$-type $\left(\mathrm{Bi}_{2} \mathrm{Te}_{3}\right)_{x}\left(\mathrm{Sb}_{2} \mathrm{Te}_{3}\right)_{1}-_{x}$ alloys by MA-HP. Phys. D 39 5069-5073 (2006).

49 Du, Z. L., Zhu, T. J., Chen, Y., He, J., Gao, H. L., Jiang, G. Y., Tritt, T. M. \& Zhao, X. B Roles of interstitial Mg in improving thermoelectric properties of Sb-doped $\mathrm{Mg}_{2} \mathrm{Si}_{0.4} \mathrm{Sn}_{0.6}$ solid solutions. J. Mater. Chem. 22, 6838-6844 (2012).

50 Stolzer, M., Stordeur, M., Sobotta, H. \& Riede, V. IR Transmission Investigations of $\left(\mathrm{Bi}_{1-\mathrm{x}} \mathrm{Sb}_{\mathrm{x}}\right)_{2} \mathrm{Te}_{3}$ Single Crystals. Phys. Status Solidi. B 138, 259-266 (1986).

51 Goldsmid, H. J. \& Douglas, R. W. The use of semi conductors in thermoelectric refrigeration. J. Appl. Phys. 5, 386-390 (1954).

52 Ivanova, L. D. \& Granatkina, Y. U. Properties of single-crystals in the $\mathrm{Sb}_{2} \mathrm{Te}_{3}-\mathrm{Bi}_{2} \mathrm{Te}_{3}$ solid-solution system. Inorg. Mater. 31, 678-681 (1995).

53 Li, J. H., Tan, Q., Li, J. F., Liu, D. W., Li, F., Li, Z. Y., Zou, M. M. \& Wang, K. BiSbTebased nanocomposites with high $\mathrm{ZT}$ : the effect of $\mathrm{SiC}$ nanodispersion on thermoelectric properties. Adv. Funct. Mater. 23, 4317-4323 (2013).

(c) (i) (5) $\fallingdotseq$ This work is licensed under a Creative Commons Attribution-NonCommercial-NoDerivs 3.0 Unported License. To view a copy of this license, visit http://creativecommons. org/licenses/by-nc-nd/3.0/

Supplementary Information accompanies the paper on the NPG Asia Materials website (http://www.nature.com/am) 